\title{
Long non-coding RNA UCA1 promotes malignant phenotypes of renal cancer cells by modulating the miR-182-5p/DLL4 axis as a ceRNA
}

Wei Wang ${ }^{1+} \mathbb{B}$, Wentao $\mathrm{Hu}^{2+}$, Ya Wang ${ }^{3+}$, Yong An ${ }^{1}$, Lei Song ${ }^{4}$, Panfeng Shang ${ }^{1 *}$ and Zhongjin Yue ${ }^{1 *}$

\begin{abstract}
Background: Accumulating literatures have indicated that long non-coding RNAs (IncRNAs) are potential biomarkers that play key roles in tumor development and progression. Urothelial cancer associated 1 (UCA1) is a novel IncRNA that acts as a potential biomarker and is involved in the development of cancers. However, the molecular mechanism of UCA1 in renal cancer is still needed to further explore.

Methods: The relative expression level of UCA1 was determined by Real-Time GPCR in a total of 88 patients with urothelial renal cancer and in different renal cancer cell lines. Loss-of-function experiments were performed to investigate the biological roles of UCA1 and miR-182-5p on renal cancer cell proliferation, migration, apoptosis and tumorigenicity. Comprehensive transcriptional analysis, dual-luciferase reporter assay and western blot etc. were performed to explore the molecular mechanisms underlying the functions of UCA1.

Results: In this study, we found that UCA1 was significantly up-regulated in renal cancer. Moreover, increased UCA1 expression was positively correlated with differentiation and advanced TNM stage. Further experiments demonstrated that knockdown of UCA1 inhibited malignant phenotypes and Notch signal path of renal cancer cells, and miR-182-5p was reverse function as UCA1. UCA1 functioned as a miRNA sponge to positively regulate the expression of Delta-like ligand 4(DLL4) through sponging miR-182-5p and subsequently promoted malignant phenotypes of renal cancer cells, thus UCA1 playing an oncogenic role and miR-182-5p as an antioncogenic one in renal cancer pathogenesis.

Conclusion: UCA1-miR-182-5p-DLL4 axis is involved in proliferation and progression of renal cancer. Thus, this study demonstrated that UCA1 plays a critical regulatory role in renal cancer cell and UCA1 may serve as a potential diagnostic biomarker and therapeutic target of renal cancer.
\end{abstract}

Keywords: UCA1, miR-182-5p, ceRNA, DLL4, Renal cancer

\footnotetext{
* Correspondence: yuezhongjin@126.com; shangpf@|zu.edu.cn

'Wei Wang, Wentao Hu and Ya Wang contributed equally to this work. 'Department of Urology, Institute of Urology, Gansu Nephro-Urological Clinical Center, Key Laboratory of Urological Diseases in Gansu Province, Lanzhou University Second Hospital, Lanzhou 730030, Gansu, China Full list of author information is available at the end of the article
}

(c) The Author(s). 2021, corrected publication 2021. Open Access This article is licensed under a Creative Commons Attribution 4.0 International License, which permits use, sharing, adaptation, distribution and reproduction in any medium or format, as long as you give appropriate credit to the original author(s) and the source, provide a link to the Creative Commons licence, and indicate if changes were made. The images or other third party material in this article are included in the article's Creative Commons licence, unless indicated otherwise in a credit line to the material. If material is not included in the article's Creative Commons licence and your intended use is not permitted by statutory regulation or exceeds the permitted use, you will need to obtain permission directly from the copyright holder. To view a copy of this licence, visit http://creativecommons.org/ licenses/by/4.0/. The Creative Commons Public Domain Dedication waiver (http://creativecommons.org/publicdomain/zero/1. $0 /$ applies to the data made available in this article, unless otherwise stated in a credit line to the data. 


\section{Introduction}

Renal cell carcinoma (RCC) accounts for approximately 3\% of all adult cancers, and poor survival is manifested in RCC patients, especially for those with metastasis [1]. RCC exerts socio-economic burden on society and the families of patients. However, the pathogenesis of RCC remains unclarified.

Various literatures reported that cancers are closely related to the abnormal expression of LNCRNA, miRNA and proteins etc., and even co-functions each other. With the rapid development of sequencing technologies, a series of dysregulated long non-coding RNAs (lncRNAs) have been found in many human diseases, especially in cancers [2-8]. Accumulating evidences suggested that long non-coding RNAs (lncRNAs) perform important or vital functions in the malignant tumors [9-15]. LncRNA urothelial cancer associated 1 (UCA1) is abnormally expressed in esophageal squamous cell carcinoma, colorectal cancer, gastric cancer melanoma cells, pancreatic cancer, thyroid cancer, lung cancer and so on [16-30]. In vitro and in vivo assays were conducted to further explore its underlying roles in tumor progression. In this study, we illustrated that UCA1 promoted tumor cell proliferation or migration and suppressed apoptosis of renal cancer and the mechanism of action.

MicroRNAs (miRNAs) are non-coding RNAs with 1825 nucleotides, which participate in various processes of tumorigenesis. The expression of miR-182-5p is not consistent across tumors. MiR-182-5p is down-regulated in ovarian cancer, colorectal cancer and renal cancer etc. However, miR-182-5p is up-regulated in Oral squamous cell carcinoma, breast cancer and hepatocellular carcinoma etc. [31-36]. However, the underlying mechanisms of miR-182-5p in the malignant behaviors of RCC are unclarified. In this study, we demonstrated that miR182-5p as negative regulatory factor were involved in the progression of renal cancer as well.

Accumulated evidences reported lncRNAs function as miRNAs sponges. This is firstly reported the relation between UCA1 and miR-182-5p as miRNAs sponges in the renal cancers in the world. This study helps broaden our knowledge of the expression pattern.

Additionally, proteins are the necessary substance to participate in lives' activities and disease progression as well, which were closely related with lncRNA and miRNA etc. Delta-like ligand 4 (DLL4), one of the ligands of Notch receptors, is predominantly expressed in the endothelial cells and has been shown to play a pivotal role in regulating tumor angiogenesis. During angiogenesis, activation of the Notch/DLL4 pathway selects the stalk cell, and promotes endothelial basement membrane formation and cell adhesion. Some studies reveal a role for DLL4 in tumorigenesis in several cancers, including $\mathrm{T}$ acute lymphoblastic leukemia (T-ALL), and glioblastoma etc. [37-47]. DLL4 is one of the ligands of Notch 1. Activation of DLL4-NOTCH signaling is important for the RCC to maintain its malignant properties.
DLL4 overexpression significantly reversed cell proliferation inhibition and migration of renal cancer cells induced by silencing UCA1, and remarkably reversed cell apoptosis promotion of renal cancer cells induced by silencing UCA1. DLL4-NOTCH signaling is critical for the progression of renal cancer cells.

In the present study, we showed that UCA1 was involved in the progression of renal cancer. Mechanistically, we found that UCA1 functioned as a miRNA sponge to positively regulate Delta-like ligand 4(DLL4) expression by sponging miR-182-5p in a ceRNA-dependent manner. Together, our results suggest that UCA1 is a powerful tumor biomarker, and UCA1-miR-182-5p-DLL4 axis is involved in proliferation, migration, apoptosis and progression of renal cancer, which highlight its potential clinical utility as a promising diagnostic and therapeutic target of renal cancer. Our findings may provide a new horizon for exploring therapeutic target of renal cancer.

\section{Materials and methods Patient samples}

Eighty eight renal cancer patients (Renal clear cell carcinoma) and 30 renal cancer patients (Papillary renal carcinoma) who received radical nephrectomy were included in this research. Renal cancer tissues and matched normal peritumoral tissues were snap-frozen in liquid nitrogen quickly after resection. Written informed consent was also obtained from all the patients. The study was approved by the institutional research ethics committee of The Second Hospital of Lanzhou University (Granted 2017A-021).

\section{Cell lines and cell culture}

Human renal cancer 786-O, Caki-1, human normal renal epithelial cells (293 T) and RPTEC (Renal Tubular Epithelial Cell) were purchased from the Institute of Cell Biology, Chinese Academy of Sciences (Shanghai, China). The 786-O cells were cultured in RPMI-1640 (1640) (HyClone, USA). The Caki-1 cell lines were cultured in McCoy's 5A (HyClone, USA). The 293 T cells were cultured in DMEM (HyClone, USA). The RPTEC cells were cultured in F12 (HyClone, USA).1640, DMEM, F12 and McCoy's 5A were mixed with $1 \%$ antibiotics $(100 \mathrm{U} / \mathrm{ml}$ penicillin and $100 \mu \mathrm{g}$ $/ \mathrm{ml}$ streptomycin sulfates) and $10 \%$ fetal bovine serum (FBS). Then plates were placed in incubator at $37^{\circ} \mathrm{C}$ with an atmosphere of $5 \% \mathrm{CO}_{2}$.

\section{Cell transfection}

Short hairpin RNAs (shRNAs) against UCA1 gene or DLL4 gene were ligated into pGPU6/GFP/Neo vectors (shUCA1, shDLL4) (Gene Pharma, Shanghai, China) and plasmid with non-targeting sequence was used as a negative control (shNC). The microRNA mimics (agomir) and microRNA inhibitor (antagomir) were purchased from 
Gene Pharma, Shanghai, China. Before transfection, the cells were cultured $24 \mathrm{~h}$. Then, the cells were transiently transfected with corresponding vector using Lipofectamine 3000 Transfection Reagent (Invitrogen, Carlsbad, CA, USA) according to the manufacturer's instructions. After $48 \mathrm{~h}$, cells transfected with corresponding vector were harvested for quantitative real-time PCR and so on. Experiments were repeated at least three times.

\section{Real-time quantitative PCR}

Total RNA was extracted from the tissues or the transfected cells using TRIzol reagent (Invitrogen, Grand Island, NY, USA) according to the manufacturer's instructions. The cDNA was synthesized from total RNA(1000 ng) using the Prime Script RT Reagent Kit with gDNA Eraser (Takara, Kyoto, Japan). The expression levels of UCA1 etc. (about 50 ng cDNA, see the relevant specifications for details) were measured by real-time quantitative PCR utilizing SYBR Premix Ex Taq II (Takara) on the CFX96 sequence detection system (Bio-Rad). The primer sequences were as follows in Additional file 1: Table S1. GAPDH and U6 small nuclear RNA were chosen as the internal control. Expressions were normalized to endogenous controls and calculated using relative quantification method $\left(2^{-\Delta \Delta C t}\right)$. Experiments were repeated at least three times.

Glyceraldehyde 3-phosphate dehydrogenase (GAPDH) or U6was chosen as the endogenous control to normalize the data.

\section{LncRNAs immunoprecipitation}

Biotin-labeled IncRNA-UCA1 probe was synthesized by RiboBio. Renal cancer cells were fixed by $1 \%$ formaldehyde for $10 \mathrm{~min}$, lysed and sonicated. After centrifugation, $50 \mu \mathrm{l}$ of the supernatant was retained as input and the remaining part was incubated with IncRNA-UCA1 specific probesstreptavidin dynabeads (M-280, Invitrogen) mixture over night at $30^{\circ} \mathrm{C}$. Next day, M-280 dynabeads-probeslncRNAs mixture was washed and incubated with $200 \mu \mathrm{l}$ lysis buffer and proteinase $\mathrm{K}$ to reverse the formaldehyde crosslinking. Finally, the mixture was added with TRIzol for RNA extraction and-qPCR detection. Renal cancer cells were lysed with radioimmunoprecipitation assay (RIPA) buffer containing protease inhibitors (Sigma).

\section{Cell proliferation assays}

Cell Counting Kit-8, CCK-8 (Beyotime Institute of Biotechnology, Shanghai, China) was used for cell proliferation according to the manufacturer's instructions. For CCK-8 assay, cells were incubated in a 96-well plate for $24 \mathrm{~h}$, and then transiently transfected with siRNAs or plasmids. The absorbance in each well was measured at 0,24 , 48 and $72 \mathrm{~h}$ after transfection by a microplate reader (BioRad, Hercules, CA, USA). Experiments were repeated at least three times.

\section{Ethynyl-2-deoxyuridine (EdU) incorporation assay}

Cell proliferation was also determined by Ethynyl-2deoxyuridine incorporation assay using an EdU Apollo DNA in vitro kit (RIBOBIO, Guangzhou, China) following the manufacturer's instructions. Briefly, after transfected with corresponding vector cells were incubated with $100 \mu \mathrm{l}$ of $50 \mu \mathrm{M}$ EdU per well for $2 \mathrm{~h}$ at $37^{\circ} \mathrm{C}$, respectively. Finally, the cells were visualized under a fluorescence microscopy. Experiments were repeated at least three times.

\section{Cell migration assay}

Cell migration was detected by scratch assay according to the reported methods [22]. Cells were seeded in 6-well plates and incubated in incubator to get $100 \%$ confluence before transfection. The cells were transfected with siRNAs or plasmids. A sterile $200 \mu \mathrm{l}$ pipette tip was used to generate a clear line in the wells. Pictures were taken from each well quickly using a digital camera system. After one day, pictures were taken again. Migration distance was counted at the time of 0 $\mathrm{h}$ and $24 \mathrm{~h}$. Experiments were repeated at least three times.

\section{Flow cytometry assay}

Renal cancer 786-O and Caki-1 cells were transiently transfected with siRNAs or plasmid vectors. $48 \mathrm{~h}$ after transfection, cells were harvested and resuspended in fixation fluid $5 \mu \mathrm{l}$ Annexin V-FIFC and $100 \mu \mathrm{l}$ propidium iodide were added to $500 \mu \mathrm{l}$ cell suspension. Cell apoptosis was then determined by using flow cytometry (EPICS, XL-4, Beckman, CA, USA). In the graphs, the quadrant respectively stands for dead cells, living cells, early apoptotic cells and late apoptotic cells. Experiments were repeated at least three times.

\section{Western blot analysis}

The transfected cells were washed with PBS, and total proteins were extracted using RIPA buffer reagent (Thermo Fisher Scientific). The concentrationofthe lysate was detected by a BCA kit (Thermo Fisher Scientific) following the manufacturer's protocol. Twenty microgram$\mathrm{s}(\mathrm{ug})$ of proteins were separated utilizing 10\% SDS-PAGE gels and then transferred into PVDF membranes. The lysates of tissues or cells with equal weight were separated by SDS-polyacrylamide gel electrophoresis (SDS-PAGE) and transferred to PVDF membranes. After blocking in the $5 \%$ milk without fat, the membranes were incubated in the primary antibodies for $16 \mathrm{~h}$ in $4{ }^{\circ} \mathrm{C}$ and then incubated with secondary antibodies at room temperature for $2 \mathrm{~h}$. Immunoblots were visualized using ECL chemiluminescent detection system and analyzed with Chem Imager $5500 \mathrm{~V} 2.03$ software. The integrated density values (IDVs) were calculated using Fluor Chem 2.0 software with $\beta$ actin as the internal standard. The following antibodies were used as followed as in Additional file 1: Table S2. Goat anti-rabbit antibody and Goat anti-mouse antibody 
(1:1000, Beyotime, Shanghai, China), Experiments were repeated at least three times.

\section{Luciferase reporter assay}

The predicted binding sites of miR-182-5p with UCA13'UTR and DLL4-3'UTR were obtained from RNAhybrid. The binding and mutant sequences were respectively cloned into pmirGLO Dual-luciferase vectors (Gene Pharma, Shanghai, China).786-O, Caki-1 and 293 T cells were cultured in 96-well plates in advance and cotransfected with the wild-type pmirGLO-UAC1 reporter plasmid or the mutated type and mimics-182-5p or NC with Lipofectamine 3000. Cells were also co-transfected with the DLL4-3'UTR reporter plasmid or the mutated type and the above listed mimics. Dual-Luciferase Reporter Assay System (Promega, Madison, WI USA) was used to analyze luciferase activity, which was recorded as the ratio of firefly luciferase activity to renilla luciferase activity. Experiments were repeated at least three times.

\section{Animal experiments}

Institutional Ethics Review Board approved this experimental procedure (Granted D2017-008). A total of 10 male immune-deficient BALB/c nude mice (5-6 wk. old) were purchased from Shanghai lingchang Laboratory Animals (Shanghai, China), and each group was 5 mice. The shUCA1 and shNC vectors were packed into lentivirus (LV-UCA1 and LV-NC) that were purchased from Gene Pharma (Gene Pharma, Shanghai, China). A total of $5 \times$ $10^{5-6}$ treated Caki-1 cells were suspended in $100 \mathrm{ml}$ Matrigel (BD Biosciences) and injected subcutaneously into the dorsal flank regions of BALB/c nude mice. Tumor growth of mice was monitored every 5 days, and mice were sacrificed 6 weeks, after inoculation. Tumor volume was calculated using the formula, $0.5 \mathrm{ab}^{2}$, where "a" and "b" meant long diameter and short diameter, respectively. Finally, mice were executed, and the subcutaneous weight of each tumor was observed. All animal experiments were approved by the Committee of Animal Experimental Ethics. Experiments were repeated at least three times.

\section{Immunofluorescence}

Immunostaining was performed on the paraffin-embedded tumor tissues from nude mice. The avidin-biotin-peroxidase method was adopted to determine the location and relative expression level of the target proteins. The primary antibodies of DLL4, was used at a dilution of 1:2000. Sections were visualized under a fluorescence microscopy (Olympus, Japan). Experiments were repeated at least three times.

\section{Statistical analysis}

All experimental assays were performed in triplicate. All data were presented as mean \pm standard deviation (SD) of triplicate biological replicates or samples. All statistical analyses were executed by using SPSS 20.0 software (IBM, Chicago, IL, USA) etc. The UCA1 RNA and miR-182-5p expression differences between renal cancer tissues and matched normal tissues were analyzed using paired samples t-test. CCK- 8 assay data were analyzed by ANOVA. The independent samples t-test was used to analyze other data. $P$ value of less than 0.05 was considered to be statistically significant.

\section{Results}

Up-regulation of UCA1 and low-expression of miR-182-5p in renal cancer tissues, cells and both correlation with clinical pathologic factors

The relative expression level of UCA1 and miR-182-5p was detected by using Real-Time qPCR in a total of 88 patients with renal cancer. Compared to matched normal peritumoral tissues, the UCA1 expression was upregulated remarkably in $68.2 \%$ (60 of 88 ) of cancer tissues $(P=0.021)$, and about 2.12 times (Fig. 1a and b), and the miR-182-5p expression was down-regulated remarkably in $72.7 \%$ (64 of 88 ) of cancer tissues $(P=$ 0.002 ) (Fig. 1c and d). Compared with the $293 \mathrm{~T}$, the UCA1 expression was increased remarkably in both renal cancer cells, 786-O $(P<0.001)$ and Caki-1 $(P<$ 0.001 ) (Fig. 1e),and the miR-182-5p expression was significantly decrease in both renal cancer cells, 786-O $(P<0.010)$ and Caki-1 $(P=0.012)$ (Fig. 1f). Compared with the RPTEC, the UCA1 expression was increased remarkably in both renal cancer cells, 786-O $(P<0.001)$ and Caki-1 $(P=0.002)$ (Fig. 1g), and the miR-182-5p expression was significantly decrease in both renal cancer cells, 786-O $(P=0.010)$ and Caki-1 $(P=0.017)$ (Fig. $1 \mathrm{~h})$. As shown in Tables 1 and 2, up-regulated UCA1 was positively associated with renal cancer differentiation $(P=0.010)$, and down-regulated miR-182-5p was positively associated with renal cancer differentiation $(P=$ $0.008)$ and TNM stage $(P=0.012)$. But gender, age, tumor size, and lymph node metastasis had no relation with UCA1 and miR-182-5p expression level. These results indicated that long non-coding UCA1 should play oncogenic role and miR-182-5p should play antioncogene one in renal cancer.

\section{Knockdown of UCA1 and up-regulation of miR-182-5p inhibited cell proliferation of renal cell lines. Up- regulation of UCA1 and down-regulation of mi-182-5p promoted cell proliferation of renal cell lines}

We further determined whether UCA1 promotes cell proliferation and miR-182-5p restrained cell proliferation in renal cancer. The relative expression level of UCA1 and miR-182-5p were analyzed by qRT-PCR at $48 \mathrm{~h}$ after transfection of shRNA, miRNA mimics or inhibitor in in 786-O and Caki-1 cell lines, and after transfection of pcDNA3.1-UCA1 in $293 \mathrm{~T}$ and RPTEC cell 


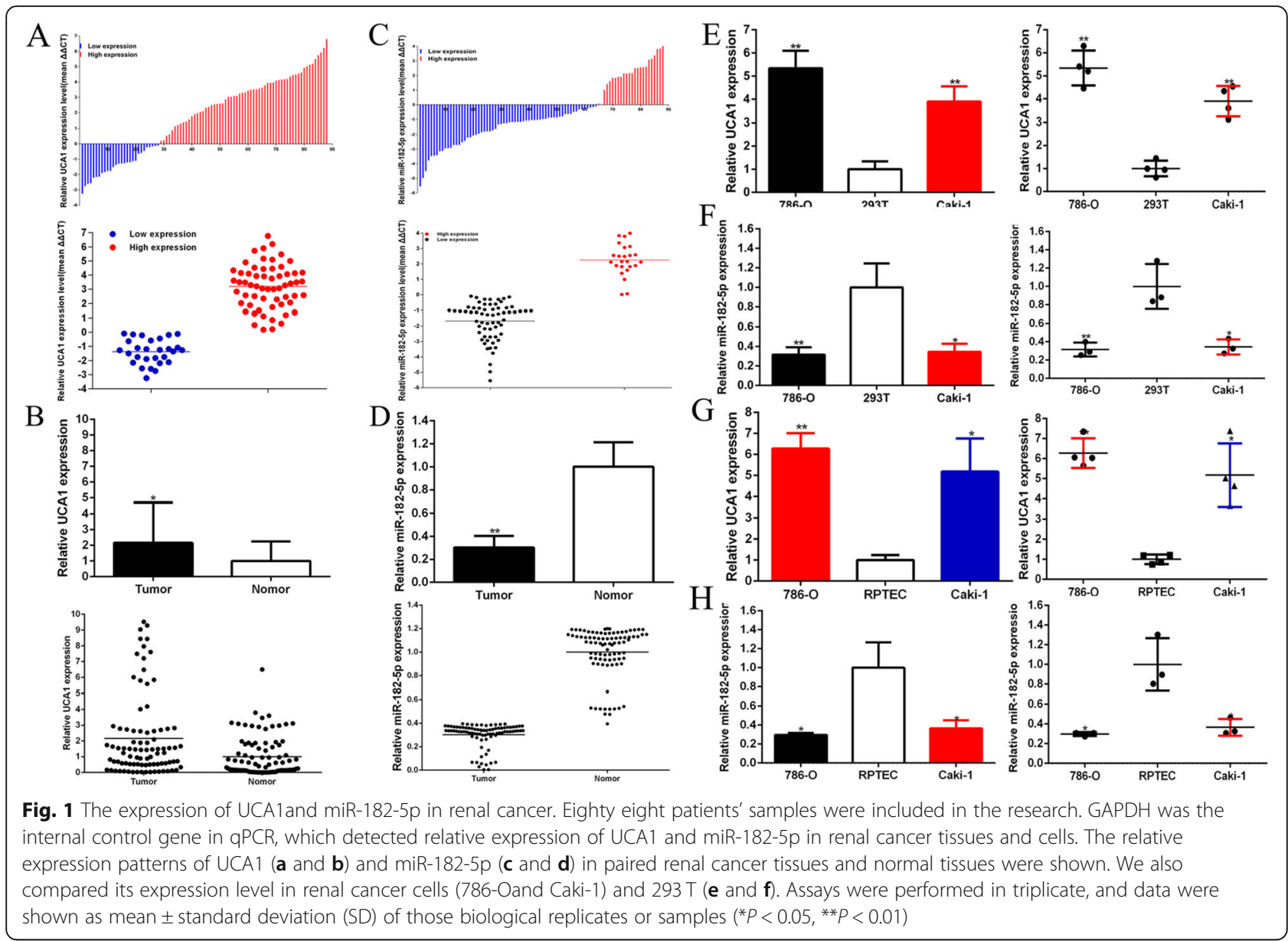

line. The relative expression levels of UCA1 was decreased by $48.17 \%$ in $786-\mathrm{O}(P=0.007)$ and was decreased by $43.84 \%$ in Caki- $1(P=0.011)$ cells were downregulated significantly by shUCA1 at $48 \mathrm{~h}$ post transfection (Fig. 2a). And the relative expression levels of UCA1 was up-regulated significantly in by 3.99 times in $293 \mathrm{~T}$ cells $(P<0.001)$ at $48 \mathrm{~h}$ post transfection of pcDNA3.1-UCA1 (Fig. 2b). And the relative expression levels of UCA1 was up-regulated significantly in by 4.026 times in RPTEC cells $(P<0.001)$ at $48 \mathrm{~h}$ post transfection of pcDNA3.1-UCA1 (Fig. 2 c). And the relative expression levels of miR-182-5p were downregulated significantly by $80.74 \%$ in $786-\mathrm{O}(P<0.001)$ and by $73.75 \%$ in Caki- $1(P<0.001)$ cells at $48 \mathrm{~h}$ post transfection of miR-182-5p inhibitor (Fig. 3a). And the relative expression levels of miR-182-5p were upregulated significantly in by 2.30 times in $786-\mathrm{O}(P<$ $0.001)$ and 2.21 times in Caki-1 $(P<0.001)$ cells at $48 \mathrm{~h}$ post transfection of miR-182-5p mimics (Fig. 3a).

CCK-8 assay was carried out to detect whether shUCA1 or miR-182-5p mimics inhibited the proliferation and pcDNA3.1-UCA1 or miR-182-5p inhibitor promoted the proliferation in 786-O, Caki-1,293 $\mathrm{T}$ and
RPTEC renal cancer cells. The results demonstrated that shUCA1(Fig. 2d and e) and miR-182-5p mimics (Fig. 3b and $c$ ) inhibited cell proliferation remarkably in both renal cancer cells $(P<0.01$ in two cell lines). PcDNA3.1UCA1 in $293 \mathrm{~T}$ and RPTEC cell lines (Fig. $2 \mathrm{f}$ and g), and miR-182-5p inhibitor in both renal cancer cells (Fig. 3b and c) promoted cell proliferation remarkably $(P<0.01$ in cell lines).

EdU assay was further illustrated to detect cell proliferation. As shown in Fig. 2h-k and Fig. 3d-e, compared to shNC, NC or negative control group, EdU positive 786-O and Caki-1 cells in shUCA1 or miR-182-5p mimics groups were reduced and pcDNA3.1-UCA1 or miR-182-5p inhibition groups were reverse after transfection.

EdU assay illustrated that the quantity of EdU positive cells in shUCA1 group was reduced by $56.37 \%$ in $786-\mathrm{O}$ $(P<0.001)$ (Fig. $2 \mathrm{~h})$ and decreased by $49.94 \%$ in Caki-1 $(P=0.002)$ (Fig. $2 \mathrm{i})$. The quantity of EdU positive cells in pcDNA3.1-UCA1 group was elevated by 2.50 times in $293 \mathrm{~T}(P=0.001)$ (Fig. $2 \mathrm{j})$. The quantity of EdU positive cells in pcDNA3.1-UCA1 group was elevated by 2.629 times in RPTEC $(P<0.001)$ (Fig. 2j). 
Table 1 Correlation between UCA1 expression and clinicopathological characteristics of renal cell cancer patients [3, 48, 49] (Clear cell renal cell carcinoma)

\begin{tabular}{|c|c|c|c|c|}
\hline \multirow[t]{2}{*}{ Characteristics } & \multirow[t]{2}{*}{ Total } & \multicolumn{2}{|c|}{ Expression of UCA1 } & \multirow{2}{*}{$\begin{array}{l}P \\
\text { value }\end{array}$} \\
\hline & & High $(n=60)$ & Low $(n=28)$ & \\
\hline \multicolumn{5}{|l|}{ Gender } \\
\hline Male & 47 & $35(74.5 \%)$ & $12(25.5 \%)$ & \multirow[t]{2}{*}{0.251} \\
\hline Female & 41 & $25(61.0 \%)$ & $16(39.0 \%)$ & \\
\hline \multicolumn{5}{|l|}{ Tumor size (cm) } \\
\hline$\leq 7 \mathrm{~cm}$ & 50 & $33(66.0 \%)$ & 17 (34.0\%) & \multirow[t]{2}{*}{0.651} \\
\hline$>7 \mathrm{~cm}$ & 38 & $27(71.0 \%)$ & $11(28.9 \%)$ & \\
\hline \multicolumn{5}{|l|}{ Age } \\
\hline$\leq 55$ & 42 & $28(66.7 \%)$ & $14(33.3 \%)$ & \multirow[t]{2}{*}{0.821} \\
\hline$>55$ & 46 & $32(69.6 \%)$ & $14(30.4 \%)$ & \\
\hline \multicolumn{5}{|l|}{ Differentiation } \\
\hline Moderate/poor & 50 & $40(68.2 \%)$ & $10(31.8 \%)$ & \multirow[t]{2}{*}{$0.010^{*}$} \\
\hline Well & 38 & $20(52.6 \%)$ & $18((47.4 \%)$ & \\
\hline \multicolumn{5}{|l|}{ TNM stage } \\
\hline T0-1 & 26 & $14(53.8 \%)$ & $12(46.2 \%)$ & \multirow[t]{2}{*}{0.080} \\
\hline T2-4 & 62 & $46(74.2 \%)$ & $16(25.8 \%)$ & \\
\hline \multicolumn{5}{|c|}{ Lymph node metastasis(N) } \\
\hline NO & 79 & $56(70.9 \%)$ & $23(29.1 \%)$ & \multirow[t]{2}{*}{0.136} \\
\hline N1 or above & 9 & 4 (44.4\%) & $5(55.6 \%)$ & \\
\hline
\end{tabular}

$\left.{ }^{*} P<0.05,{ }^{* *} P<0.01\right)$

TNM according to staging TNM of American Joint Committee on Cancer (AJCC) in 2010

The quantity of EdU positive cells in miR-182-5p mimics group was reduced by $44.47 \%$ in $786-\mathrm{O}(P=$ $0.005)$ and decreased by $51.17 \%$ in Caki-1 $(P=0.005)$ (Fig. 3d and e). The quantity of EdU positive cells in miR-182-5p inhibitor group was elevated by 1.52 times in $786-\mathrm{O}(P=0.010)$ and raised by1.76 times in Caki-1 $(P=0.016)$ (Fig. 3d and e).

These results demonstrated that knockdown of UCA1 and elevation of miR-182-5p inhibited cell proliferation in renal cell lines and up-regulation of UCA1 and inhibition of miR-182-5p promoted cell proliferation of renal cell lines.

Knockdown of UCA1 and up-regulation of miR-182-5p inhibited cell migration of renal cell lines. Up-regulation of UCA1 and down-regulation of mi-182-5p promoted cell migration of renal cell lines

Cells were transfected with plasmids, mimics or inhibitor in 6-well plates. The cell scratch assay was utilized to detect the role of plasmids, mimics or inhibitor in cell migration. Compared with shNC group, cell migration of renal cancer cells was significantly suppressed by shUCA1 and miR-182-5p mimics. Scratch assay illustrated that the ratio of the relative migration in shUCA1 group was reduced
Table 2 Correlation between miR-182-5p expression and clinicopathological characteristics of renal cell cancer patients [3, 48, 49] (Clear cell renal cell carcinoma)

\begin{tabular}{|c|c|c|c|c|}
\hline \multirow[t]{2}{*}{ Characteristics } & \multirow[t]{2}{*}{ Total } & \multicolumn{2}{|c|}{ Expression of miR-182-5p } & \multirow{2}{*}{$\begin{array}{l}P \\
\text { value }\end{array}$} \\
\hline & & $\operatorname{High}(n=24)$ & Low $(n=64)$ & \\
\hline \multicolumn{5}{|l|}{ Gender } \\
\hline Male & 47 & $11(23.4 \%)$ & $36(76.6 \%)$ & \multirow[t]{2}{*}{0.474} \\
\hline Female & 41 & $13(31.7)$ & $28(68.3 \%)$ & \\
\hline \multicolumn{5}{|l|}{ Tumor size (cm) } \\
\hline$\leq 7 \mathrm{~cm}$ & 50 & $16(32.0 \%)$ & $34(68.0 \%)$ & \multirow[t]{2}{*}{0.335} \\
\hline$>7 \mathrm{~cm}$ & 38 & $8(21.1 \%)$ & $30(78.9 \%)$ & \\
\hline \multicolumn{5}{|l|}{ Age } \\
\hline$\leq 55$ & 43 & 15 (34.9\%) & $28(65.1 \%)$ & \multirow[t]{2}{*}{0.152} \\
\hline$>55$ & 45 & $9(20.0 \%)$ & $36(80.0 \%)$ & \\
\hline \multicolumn{5}{|l|}{ Differentiation } \\
\hline Moderate/poor & 50 & $8(16.0 \%)$ & $42(84.0 \%)$ & \multirow[t]{2}{*}{$0.008^{* *}$} \\
\hline Well & 38 & $16(42.1 \%)$ & $22((57.9 \%)$ & \\
\hline \multicolumn{5}{|l|}{ TNM stage } \\
\hline T0-1 & 26 & $12(11.5 \%)$ & $14(88.5 \%)$ & \multirow[t]{2}{*}{$0.017^{*}$} \\
\hline $\mathrm{T} 2-4$ & 62 & $12(38.7 \%)$ & $50(61.3 \%)$ & \\
\hline \multicolumn{5}{|c|}{ Lymph node metastasis(N) } \\
\hline No & 79 & $21(26.6 \%)$ & $58(73.4 \%)$ & \multirow[t]{2}{*}{0.700} \\
\hline N1 or above & 9 & 3 (33.3\%) & 6 (66.7\%) & \\
\hline
\end{tabular}

(*P $<0.05, * * P<0.01)$

TNM according to staging TNM of American Joint Committee on Cancer (AJCC) in 2010

by $44.35 \%$ in $786-\mathrm{O}(P=0.009)$ (Fig. $4 \mathrm{a})$ and decreased by 42.23\% in Caki-1 $(P=0.008)$ (Fig. $4 b)$.

The ratio of the relative migration in miR-182-5p mimics group was reduced by $41.12 \%$ in $786-\mathrm{O}(P=0.008)$ and decreased by $40.6 \%$ in Caki-1 $(P<0.001)$ (Fig. $4 \mathrm{c}$ and $\mathrm{d})$. The ratio of the relative migration in miR-182-5p inhibitor group was elevated by 1.51 times in $786-\mathrm{O}(P=0.001)$ and raised by1.58 times in Caki-1 ( $P=0.005)$ (Fig. $4 \mathrm{c}$ and $\mathrm{d})$. The ratio of the relative migration in pcDNA3.1-UCA1 group was increased by 2.02 times in $293 \mathrm{~T}(P=0.011)$ (Fig. 4e). The ratio of the relative migration in pcDNA3.1-UCA1 group was increased by 2.014 times in RPTEC $(P<0.001)$ (Fig. 4f).

These data suggested that knockdown of UCA1 and up-regulation of miR-182-5p inhibited cell migration of renal cell lines. Up-regulation of UCA1 and downregulation of mi-182-5p promoted cell migration of renal cell lines.

Knockdown of UCA1 and up-regulation of miR-182-5p promoted cell apoptosis of renal cell lines. Up-regulation of UCA1 and down-regulation of mi-182-5p suppressed cell apoptosis of renal cell lines

Furthermore, we asked whether knockdown or overexpression of UCA1 and miR-182-5p can regulate cell 


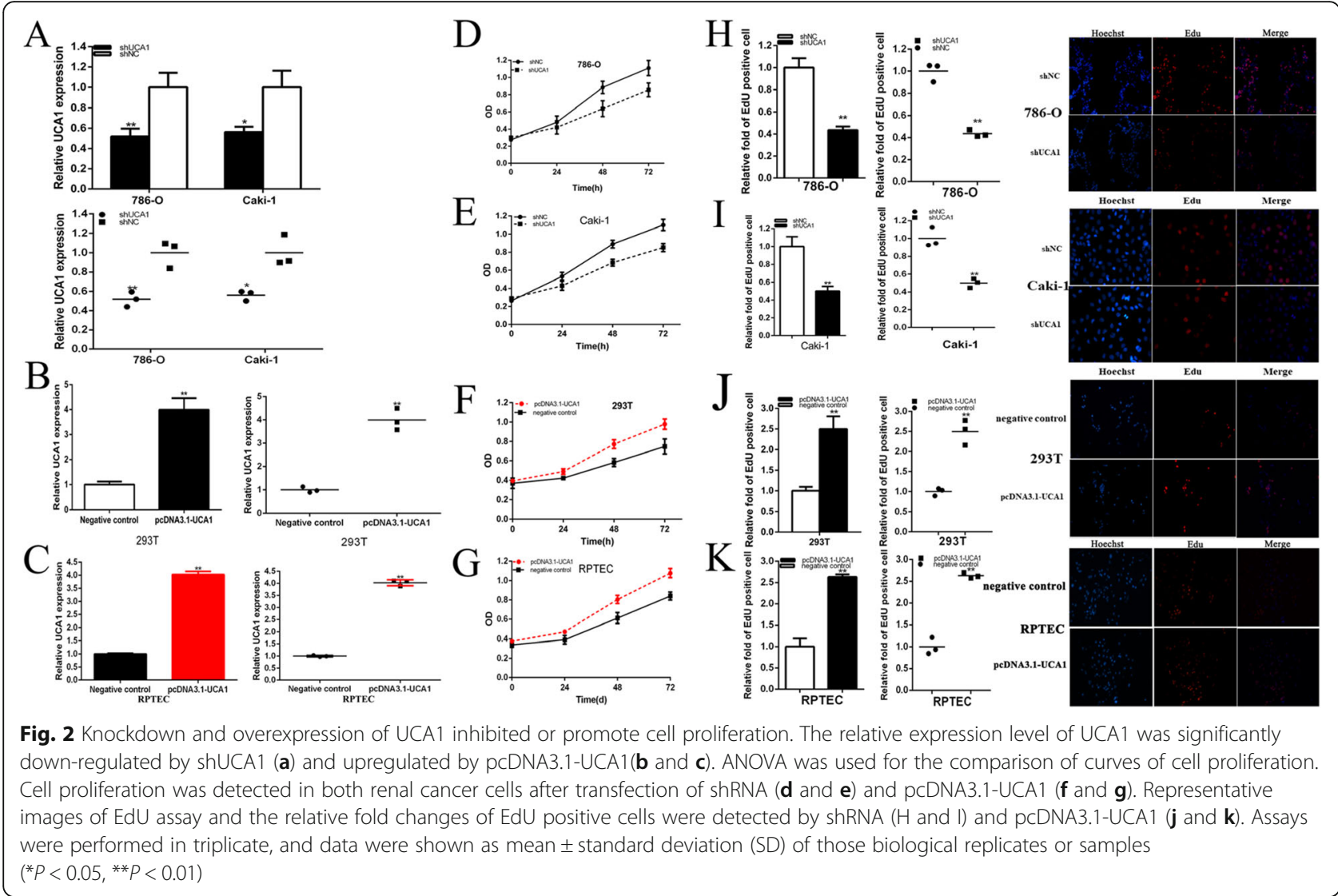

apoptosis in renal cell lines after transfection of plasmids and miR-182-5p mimics or inhibitor and cell apoptosis was detected by flow cytometry assay. The apoptotic cells were increased remarkably in both cell lines after transfection with the shUCA1 as revealed by flow cytometry assay. Compared with control groups, the ratios of apoptosis were increased significantly by 2.58 times in $786-\mathrm{O}(P<0.001)$ and raised by2.81 times in Caki-1 $(P<0.001)$ (Fig. 5a and b) after transfected with the shUCA1.

Compared with control groups, the ratios of apoptosis were decreased significantly by55.20\% in RPTEC $(P<$ 0.001) (Fig. 5c) after transfected with the pcDNA3.1UCA1.Compared with control groups, the ratios of apoptosis were decreased significantly by $65.22 \%$ in 293 $\mathrm{T} \quad(P<0.001) \quad$ (Fig. 5d) after transfected with the pcDNA3.1-UCA1.

Compared with control groups, the ratios of apoptosis were increased significantly by1.57 times in 786-O $(P<$ $0.001)$ and raised by 2.22 times in Caki-1 $(P<0.001)$ (Fig. 5e and $\mathrm{f}$ ) after transfected with the miR-182-5p mimics. Compared with control groups, the ratios of apoptosis were decreased significantly by $51.68 \%$ in 786 O $(P=0.002)$ and reduced by $54.54 \%$ in Caki-1 $(P=$ 0.003 ) (Fig. 5e and f) after transfected with the miR-182$5 \mathrm{p}$ inhibitor.
In a word, knockdown of UCA1 and up-regulation of miR-182-5p promoted cell apoptosis of renal cell lines and up-regulation of UCA1 and down-regulation of mi182-5p suppressed cell apoptosis of renal cell lines.

\section{UCA1 was a target of miR-182-5p}

Compared with shNC groups, the expressions of miR182-5p were up-regulated by 3.494 times in 786-O $(P<$ $0.001)$ and by 2.795 times in Caki-1 $(P=0.003)$ (Fig. 6a) in shUCA1 groups. Compared with shNC co-transfected $\mathrm{NC}$ groups, the expressions of miR-182-5p were upregulated by 4.36 times in $786-\mathrm{O}(P<0.001)$ and by 4.37 times in Caki-1 $(P<0.001)$ (Fig. 6b) in shUCA1 cotransfected miR-182-5p mimics groups. Conversely, miR-182-5p inhibitor partially reversed the upregulation expression effects of miR-182-5p induced by shUCA1, and decreased by $56.16 \%$ in $786-\mathrm{O}$ and by $48.47 \%$ in Caki-1 cell lines. Compared with negative control groups, the expressions of miR-182-5p was down-regulated by 63.43\%in $293 \mathrm{~T}(P<0.001)$ in pcDNA3.1-CUCA1 groups (Fig. 6c).

Since lncRNAs can function as sponges or inhibitors of their interacting miRNAs, lncRNAs interacting with miRNAs were predicted. We wondered whether lncRNA exerted its effect through sponging miRNAs. The potential binding sites of UCA1 with miR-182-5p were 


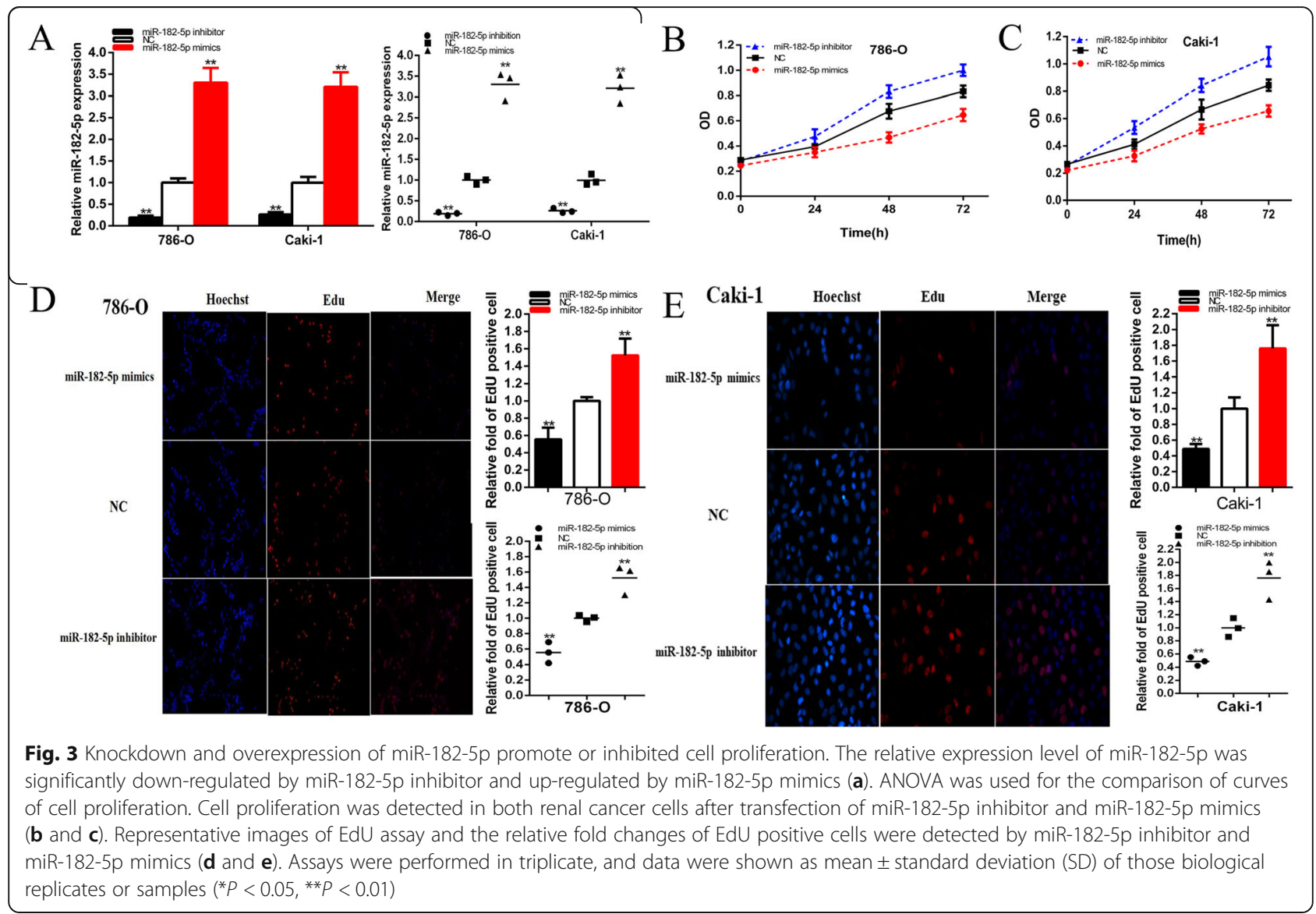

predicted using RNAhybrid. Luciferase reporter assay was performed to confirm the predictions. We found that miR-182-5p mimics significantly inhibited luciferase activity of wild type reporter for lncRNA-UCA1, compared with the group of co-transfections with $\mathrm{NC}$ and pmirGLO-UCA1-Wt, the luciferase activity was decreased by $41.00 \%$ in $786-0(P<0.001)$ and by $50.1 \%$ in Caki-1 $(P<0.001)$ in the group of cotransfections with miR-182-5p mimics and pmirGLOUCA1-Wt,however, miR-182-5p did not inhibit the luciferase activity of reporter vector containing the mutant binding sites of lncRNA-UCA1 (Fig. 6d). It has been known that miRNAs repress translation and degrade mRNA in an AGO2-dependent manner by binding to their targets. We conducted anti-AGO2 immunoprecipitation (RIP) in renal cells transiently overexpressing miR-182-5p to pull down the IncRNAUCA1 using anti-AGO2 antibodies or control IgG, followed by RT-qPCR analysis for IncRNA-UCA1 levels. The results showed that lncRNA-UCA1 pulled down with anti-Ago2 antibodies was significantly enriched in cells transfected with miR-182-5p mimics compared to controls. (Fig. 6e), suggesting that miR182-5p could directly target lncRNA-UCA1 in AGO2dependent manner.
The suppressive effects on renal cancer cells induced by UCA1 knockdown was mediated by miR-182-5p

After the luciferase reporter and RIP assay, UCA1 was confirmed to be a target of miR-182-5p. Whether miR182-5p was involved in the inhibitory effects of shUCA1 renal cancer cells needed to be clarified. Cells that were stably transfected with shUCA1 were co-transfected with miR-182-5p mimics and showed stronger inhibitory effects on the proliferation (Fig. 6f-i), and migration(Fig. $7 \mathrm{a}-\mathrm{d}$ ) of renal cancer cells than the cells co-transfected with shNC co-transfected $\mathrm{NC}(\mathrm{shNC}+\mathrm{NC})$, while apoptosis was significantly enhanced in shUCA1 cotransfected miR-182-5p(shUCA1 + miR-182-5p) group compared with shNC+NC group(Fig. 8a-d). Conversely, miR-182-5p inhibitor partially reversed the tumor suppressive effects induced by shUCA1.

The CCK- 8 assay results demonstrated that shUCA1 co-transfected miR-182-5p(Fig. 6f and g) remarkably inhibited cell proliferation in both renal cancer cells $(p<0.01$ in $786-\mathrm{O}$ and $p<0.05$ in Caki-1).Meantime, miR-182-5p inhibitor partially reversed the tumor suppressive effects induced by shUCA1 as what have been above (Fig. $6 \mathrm{f}$ and g) .

As shown in Fig. $6 \mathrm{~h}$ and $\mathrm{i}$, compared to shNC cotransfected $\mathrm{NC}(\mathrm{shNC}+\mathrm{NC})$, EdU positive cells in 


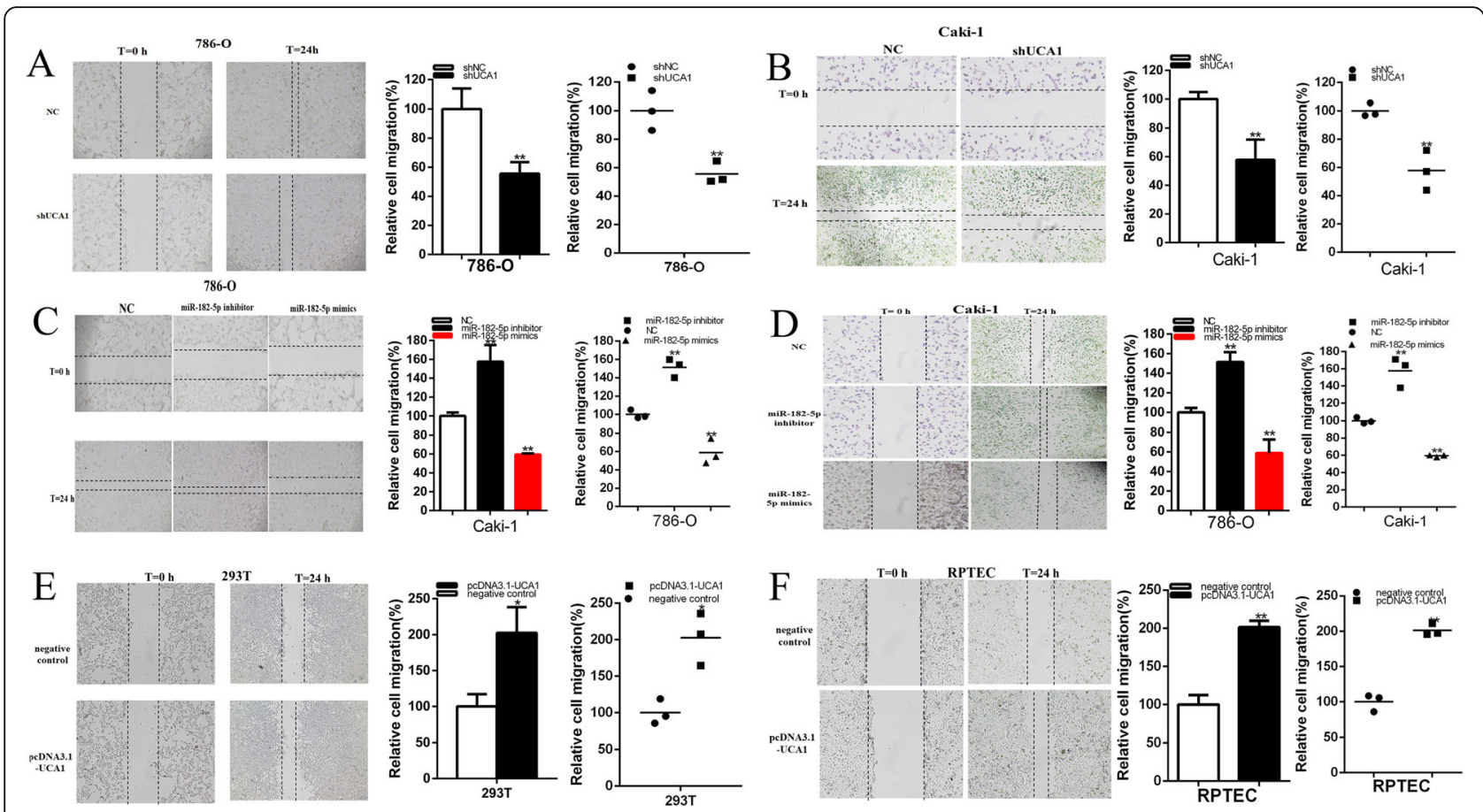

Fig. 4 UCA1 and miR-182-5p impacted the renal cancer cell migration. The relative cell migration was suppressed after transfection of shRNA in the 786-O and Caki-1 (a and $\mathbf{b})$ cell lines. The relative cell migration was suppressed or promoted after transfection of miR-182-5p mimics or inhibitor in the 786-O and Caki-1 (c and $\mathbf{d}$ ) cell lines. The relative cell migration was promoted after transfection of pcDNA3.1-UCA1 in the 293 T and RPTEC cell lines (e and $\mathbf{f}$ ). Assays were performed in triplicate, and data were shown as mean \pm standard deviation (SD) of those biological replicates or samples $\left({ }^{*} P<0.05,{ }^{* *} P<0.01\right)$

shUCA1 co-transfected miR-182-5p mimics groups were significantly reduced by $55.89 \%$ in $786-0(P<0.001)$ and by $65.67 \%$ in $\operatorname{Caki-1}(P=0.001)$ (Fig. $6 \mathrm{~h}$ and i). Conversely, miR-182-5p inhibitor partially reversed the EdU positive suppression induced by shUCA1, and increased by $37.12 \%$ in $786-\mathrm{O}$ and by $42.59 \%$ in Caki- 1 cell lines (Fig. $6 \mathrm{~h}$ and i).

Compared to shNC+NC, the ratio of the relative migration in shUCA1 co-transfected miR-182-5p mimics groups were significantly reduced by $51.94 \%$ in $786-0(P=0.002)$ and by $53.65 \%$ in Caki-1 $(P<0.001)$. Correspondingly, miR-182-5p inhibitor partially reversed the ratio of the relative migration suppression induced by shUCA1, and increased by $20.62 \%$ in 786-O and by $18.63 \%$ in Caki-1 cell lines (Fig. 7a-d).

Compared to shNC+NC, the apoptosis in shUCA1 cotransfected miR-182-5p mimics groups were significantly elevated by 2.28 times in $786-0(P<0.001)$ and by 2.47 times in Caki-1 $(P<0.001)$. On the contrary, miR-182-5p inhibitor partially reversed the apoptosis accelerator induced by shUCA1, and decreased by $69.14 \%$ in $786-\mathrm{O}$ and by $90.47 \%$ in Caki-1 cell lines (Fig. 8a-d).

\section{UCA1 positively regulates DLL4 expression via sponging miR-182-5p}

The putative binding sites of DLL4 with miR-182-5p was predicted by the bioinformatics databases. While the binding sites were shown in Fig. 9a. Luciferase reporter assay was performed to verify the binding sites and binding effects. We found that miR-182-5p mimics significantly inhibited luciferase activity of wild type reporter for DLL4, compared with the group of co-transfections with NC and pmirGLO-UCA1-Wt, luciferase activity was decreased by $47.93 \%$ in $786-0(P<0.001)$ and by $64.83 \%$ in Caki-1 $(P=0.001)$ was observed in cells cotransfected of miR-182-5p and DLL4C-3'UTR-Wt,however, miR-182-5p did not inhibit the luciferase activity of reporter vector containing the mutant binding sites of DLL4 (Fig. 9a).

The results showed that UCA1 expression levels were statistically positively correlated with DLL4 expression levels in renal cancer cell lines and knockdown of UCA1 decreased DLL4 expression in renal cancer cells. Moreover, knockdown of DLL4 regulated Notch Signaling of renal cancer cells (Fig. 9b and c). The expression of Notch Signaling markers were determined using qRTPCR, and western blotting. Knockdown of UCA1 increased DLL1, Jag1, Jag2 and Notch1expression and decreased DLL4, NICD and Hes1 expression in renal cancer cells.

We further determined whether UCA1 regulated the expression of DLL4 in renal cancer cells via miR-182$5 \mathrm{p}$-dependent manner. We found overexpressing miR- 


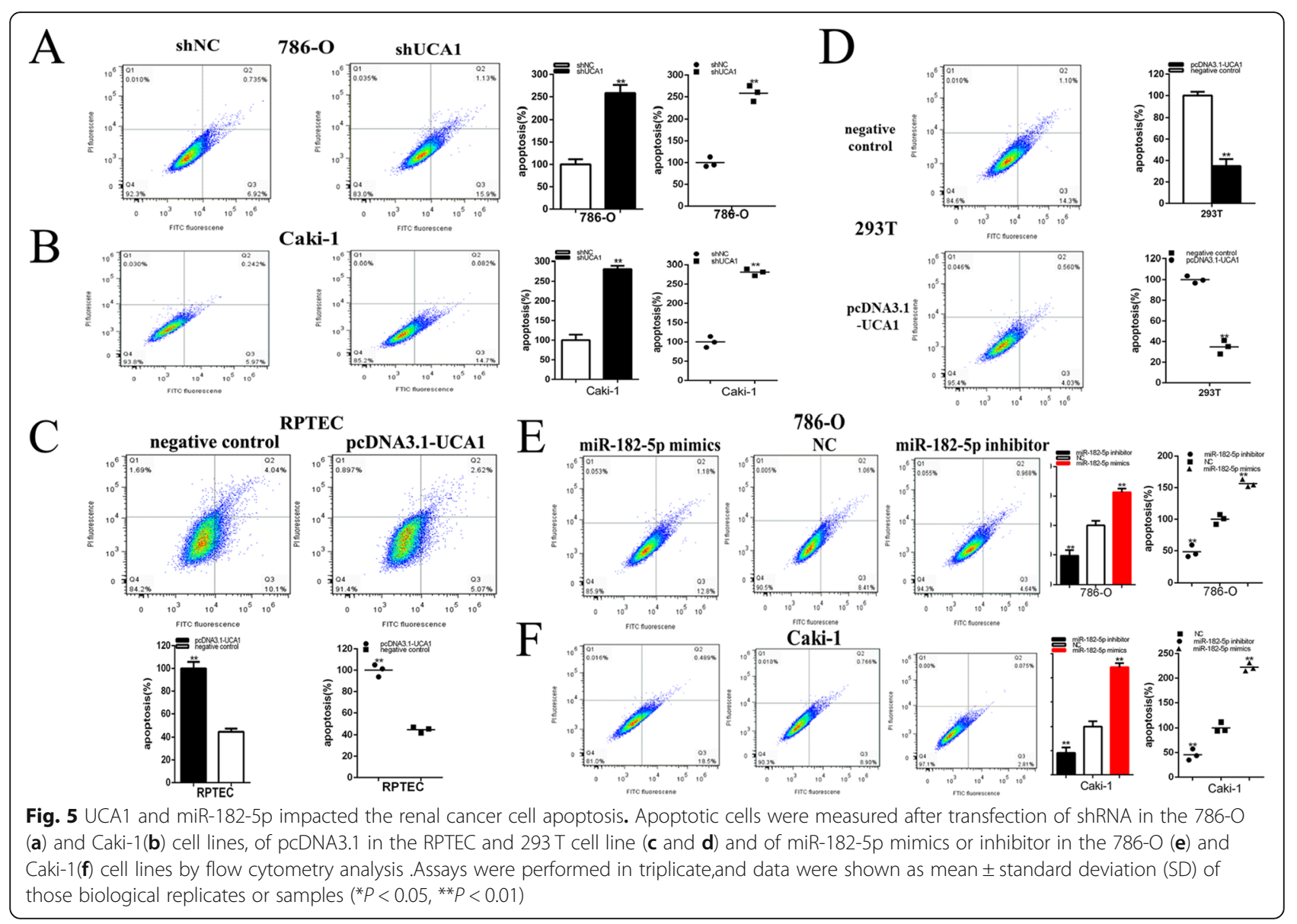

182-5p decreased DLL4 expression in renal cancer cells (Fig. 9d and e). The results indicated that UCA1 positively regulates DLL4 expression via sponging miR-182$5 p$ in renal cells.

\section{Overexpressing of DLL4 reverses malignant phenotypes} inhibition of renal cancer cells induced by silencing UCA1 We further determined whether DLL4 regulated malignant phenotypes of renal cancer cells via DLL4dependent manner. Our results showed that the DLL4 specific vector (pcDNA3.1-DLL4) significantly reversed the inhibition of DLL4 expression induced by silencing UCA1 in renal cancer cells (Fig. 9f and g). Meanwhile, we found DLL4 overexpression significantly reversed cell proliferation inhibition of renal cancer cells (Fig. 9h) induced by silencing UCA1. And DLL4 overexpression significantly reversed cell migration (Fig. $9 \mathrm{i}$ and $\mathrm{j}$ ) of renal cancer cells induced by silencing UCA1. Moreover, DLL4 overexpression significantly reversed cell apoptosis promotion of renal cancer cells (Fig. 9k and $\mathrm{l}$ ) induced by silencing UCA1. The results indicated that UCA1 promotes malignant phenotypes of renal cancer cells via DLL4-dependent manner.

\section{Knockdown of UCA 1 inhibits tumorigenicity of renal cancer cells}

We further determined whether UCA1 regulated tumorigenicity of renal cancer cells using generation of xenograft. We found knockdown of UCA1 inhibited the tumorigenicity of renal cancer cells in vivo (Fig. 10a-g). Tumors collected from mice were exhibited and measured (Fig. 10a). We found that decreased UCA1 expression was remarkably decreased compared to the LV-NC group of renal cancer cells in vivo (Fig. 10b). Tumor weight of LV-NC treatment group was greater than that in theLV-UCA1 group (Fig. 10c). Tumor growth of LV$\mathrm{NC}$ treatment group was faster than that in the LVUCA1 group (Fig. 10d). We found knockdown of UCA1 increased DLL1, Jag1, Jag2 and Notch1expression and decreased DLL4, NICD and Hes1 expression of renal cancer cells in vivo (Fig. 10e and f). Meanwhile, we found knockdown of UCA1 decreased DLL4 expression (Fig. 10g) of renal cancer cells in vivo. The results indicated that UCA1 promoted tumorigenicity of renal cancer cells via upregulating DLL4. As shown in Fig. 11, we found that UCA1 was significantly upregulated in renal cancer cells and UCA1 functioned as a miRNA sponge to positively regulate DLL4 expression through sponging 


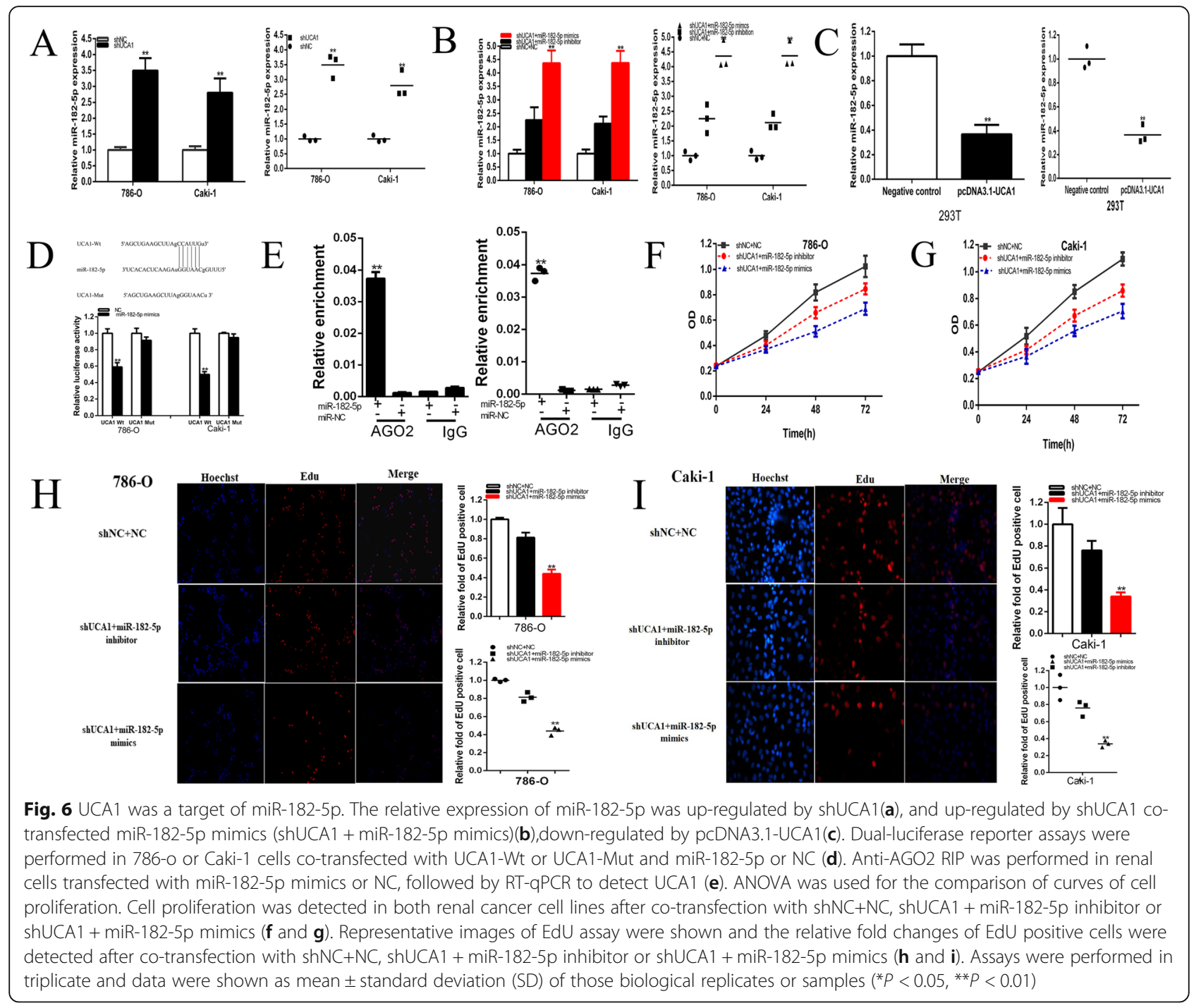

miR-182-5p. Elevated DLL4 protein promoted transcription and translation of proteins operating in essential oncogenic signaling pathways, subsequently promoting malignant phenotypes of renal cancer cells.

\section{Discussion}

The lncRNAs are important new members of noncoding RNA family, which are longer than 200 nucleotides. Accumulating evidences suggest that long noncoding RNAs (lncRNAs) perform important functions in regulation of genes which control tumor proliferation, apoptosis, and migration etc., and stretched our understanding of the biological behavior in diseases especially in carcinomas including renal cancer [2-10]. Furthermore, these previous studies indicate that lncRNAs are valuable biomarkers and therapeutic targets $[11-15,50]$. The Long non-coding RNA UCA1 was located in chromosome 9p13.12, and has been found to be overexpressed in tumor tissues, such as esophageal squamous cell carcinoma,colorectal cancer, ovarian cancer, bile duct carcinoma and melanoma etc. [16-23].UCA1 are participated in the tumorigenesis and progression, functioning as an oncogene [24-30]. However, the relation between UCA1 and renal cancer is still unknown and mysterious particularly.

This is the first report to illustrate the function of UCA1 and miR-182-5p in renal cancer. In this research, we evaluated the expression patterns and clinical significances of UCA1 in renal cancer, and furthermore explored its possible function in renal cancer cells. Our study validated that UCA1 and miR182-5p can be considered as a promising biomarker for the diagnosis of renal cancer. The expression of UCA1 was remarkably higher in renal cancer tissues and cell lines, and its up-regulation was positively correlated with differentiation and TNM stage in renal cancer. Furthermore, we explored the function of UCA1 in renal cancer cells and found that 

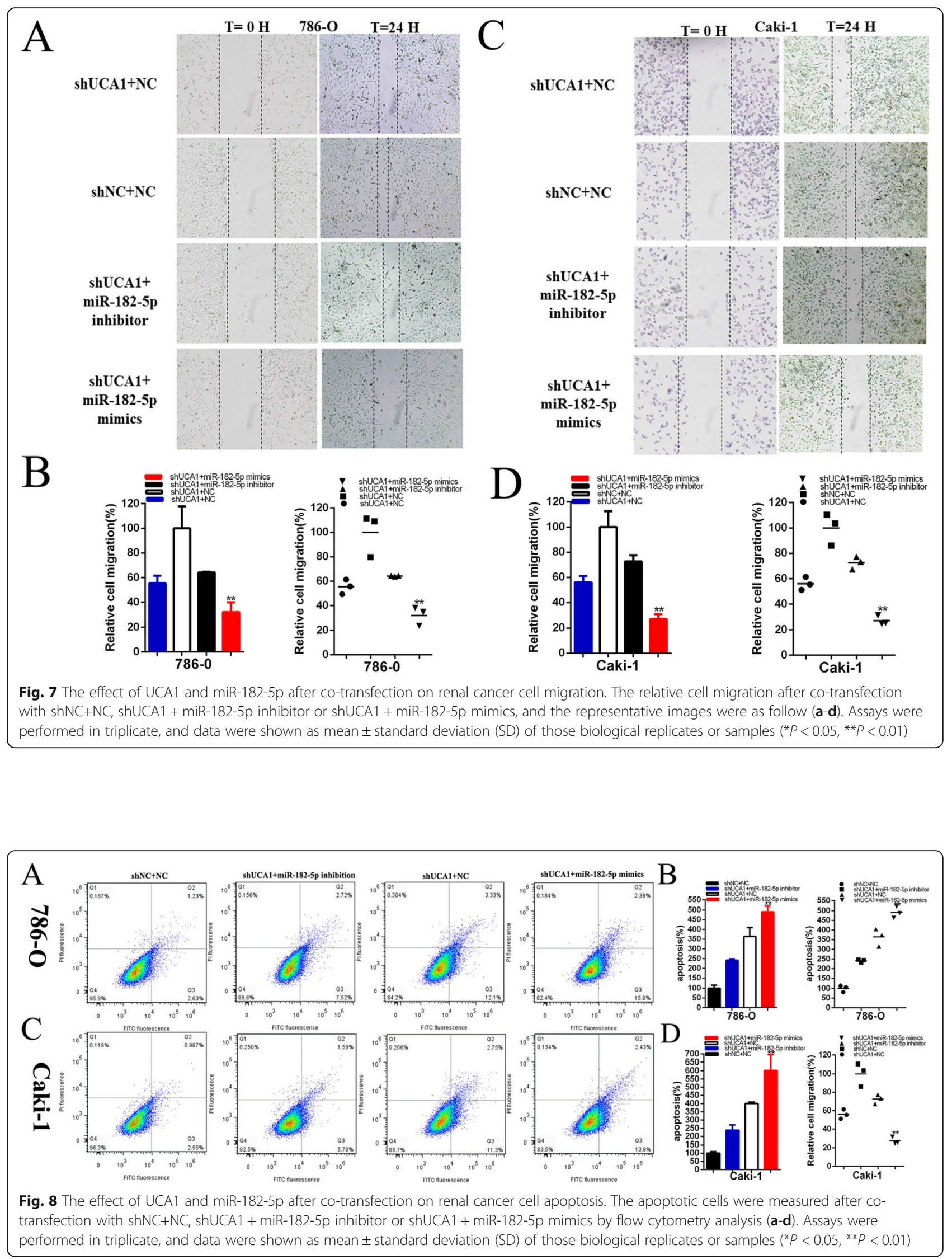


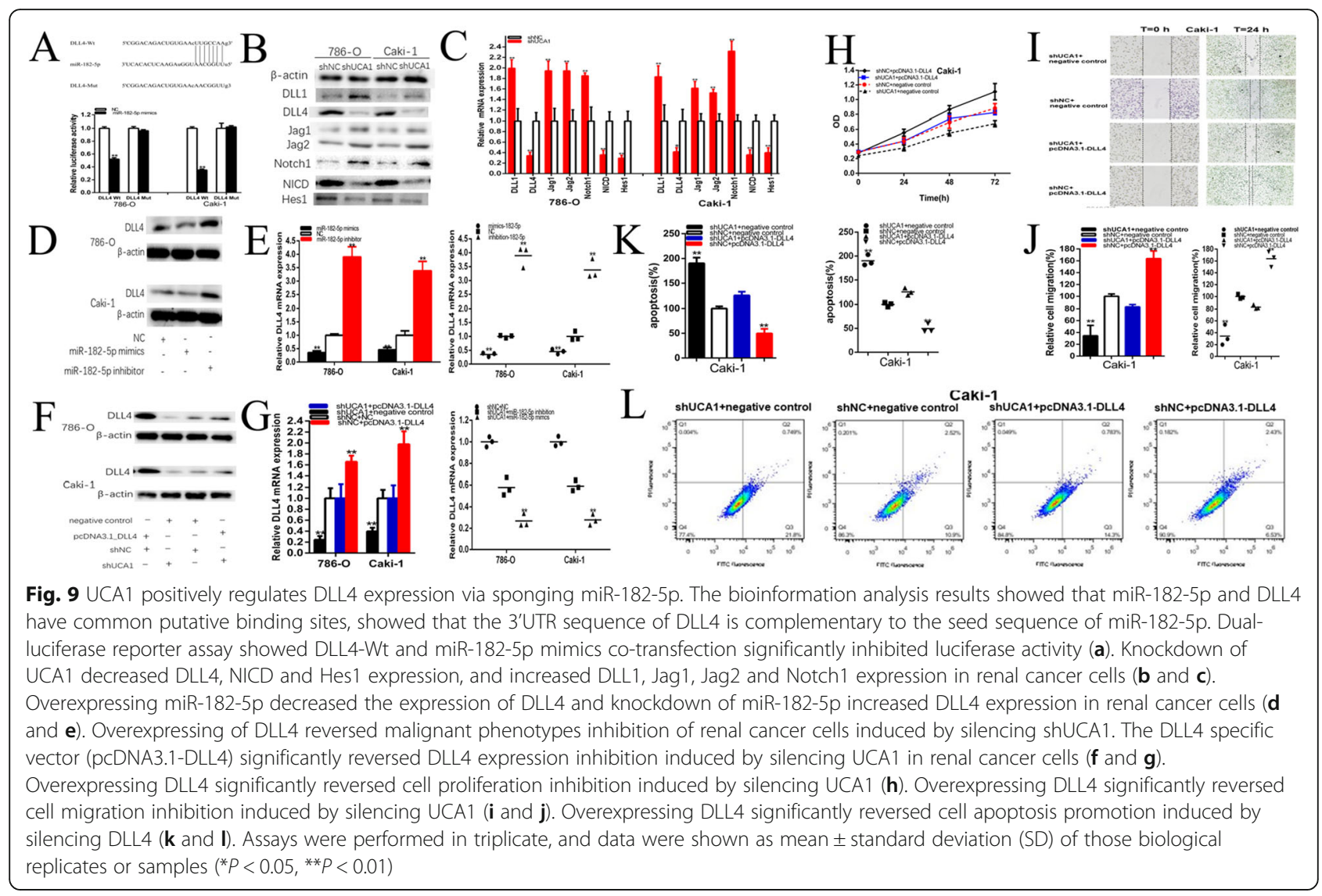

inhibition of UCA1 expression through UCA1 shRNA could suppress tumor cell proliferation, inhibited cell migration and induced apoptosis etc. To get a better insight to the role of UCA1, we over-expressed UCA1 in $293 \mathrm{~T}$ and PRTEC cell lines and it is found that overexpression of UCA1 could promote cell proliferation, migration and anti-apoptosis. In vivo studies demonstrated that UCA1 knockdown induced the smallest tumor volume and weight and so on in nude mice.

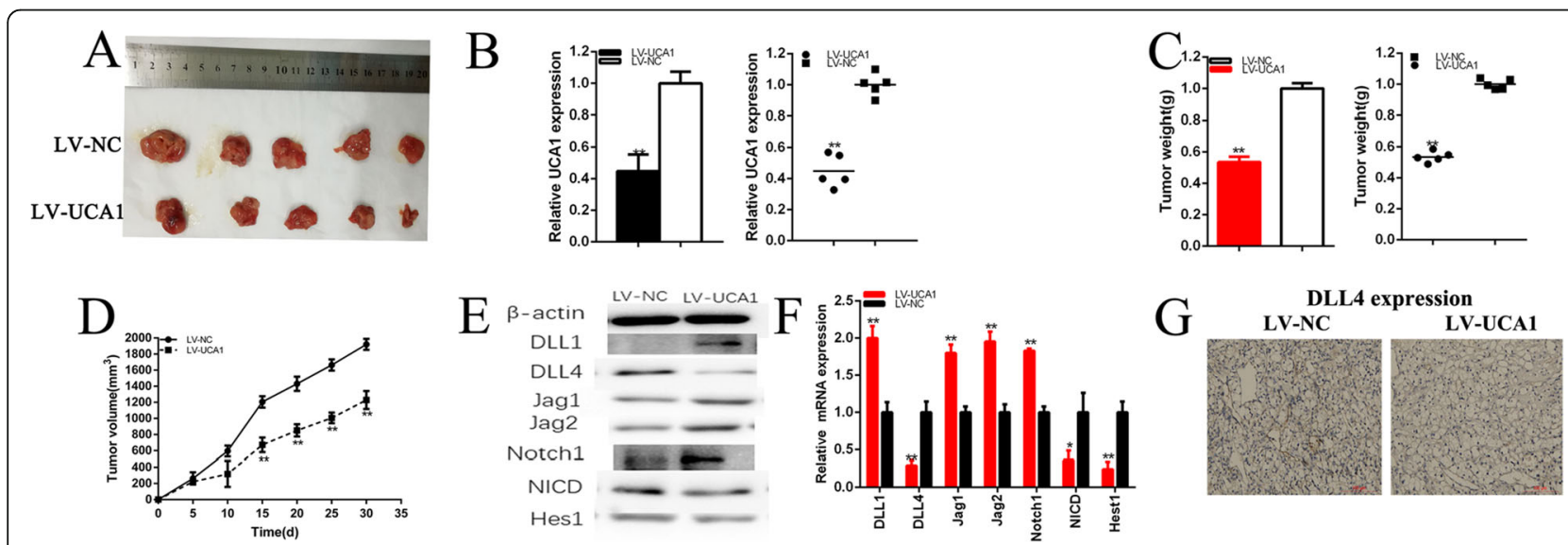

Fig. 10 The effect of UCA1 on tumorigenicity of renal cancer cells. Tumors collected from mice were exhibited (a). The relative expression level of UCA1 was significantly down-regulated by LV-UCA1 (b). Tumor weight of LV-UCA1 or LV-NC treatment groups were measured and analyzed (c). Tumor volume curve of LV-UCA1 or LV-NC treatment groups were measured and analyzed (d). Knockdown of UCA1 decreased DLL4, NICD and Hes1 expression, and increased DLL1, Jag1, Jag2 and Notch1 expression in renal cancer cells (e and $\mathbf{f}$ ). Knockdown of UCA1 decreased DLL4 expression of renal cancer cells in vivo $(\mathbf{g})$. Data were shown as mean \pm standard deviation (SD) of those biological replicates or samples $\left({ }^{*} P<0.05,{ }^{* *} P<0.01\right)$ 


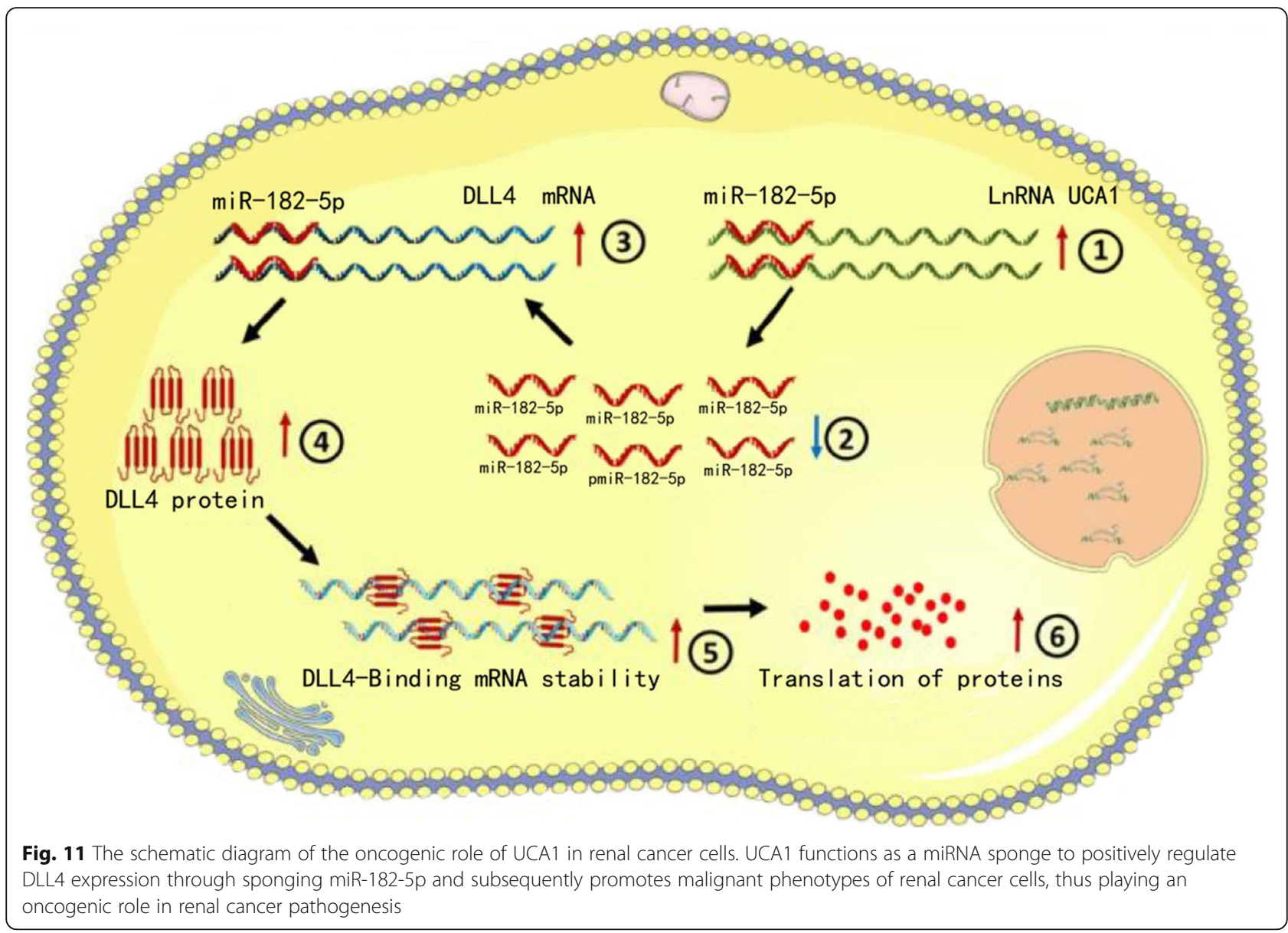

Accumulated evidences indicate the reciprocal inhibition between lncRNAs and miRNAs [16, 20, 22, 24, 25, 28-30], and our study is also a good example on the relation furthermore. LncRNAs function as miRNAs sponges or decoys that titrate the concentration of miRNAs and therefore prevent miRNAs binding specific mRNAs. The role of UCA1 as a miRNA sponge in neoplasms has been reported in several studies. UCA1 promotes the progression of melanoma by sponging miR-28-5p [22]. In Prostate cancer, UCA1 works as an oncogene by targeting miR-204 [28]. The above studies are consistent with our research. As lncRNAs could function as sponges, they also might be saturated with miRNAs. Therefore, distinct expressions of lncRNAs and miRNAs in different tissues may induce different binding actions. Bioinformatics prediction was performed in order to investigate the underlying mechanism of UCA1 in renal cancer in our study, and miR-182-5p were predicted as potential targets. The prediction was confirmed by luciferase assay, and meanwhile miR-182-5p was found to be up-regulated in UCA1 knockdown cell lines. Furthermore, miR-182-5p were found to be downregulated in renal cancer specimens and cell lines. And its down-regulation was positively correlated with differentiation and TNM stage in renal cancer. Over-expression of
miR-182-5p respectively inhibited the malignant behaviors of renal cancer cells, and inhibited cell proliferation, migration and promoted apoptotic while the opposite effects were found in renal cancer cells with down-regulated miR182-5p. MiR-182-5p plays tumor-suppression and antiangiogenesis roles through altering the microenvironment and regulating DLL4 expression. Furthermore, we found that UCA1 knockdown combined with miR-182-5p overexpression significantly suppressed the malignant behaviors of renal cancer cells. Down-regulation of miR-182-5p could partially rescue the inhibition induced by UCA1 knockdown. This suggested that the suppression of malignancy caused by UCA1 knockdown might result from upregulating of miR-182-5p.

As we known, miRNAs regulate lives' activities by means of the protein indirect role and regulate target genes by binding to the 3'UTR of specific mRNAs and cause degradation or transcriptional inhibition of target genes [31-36]. Biological softwares were used to predict the possible target genes of miR-182-5p to investigate the mechanisms of these miRNAs in renal cancer. DLL4 was a shared target gene of miR-182-5p, which was identified by luciferase reporter assay. Overexpression of miR-182-5p suppressed DLL4 protein expression, while 
down-regulation of miR-182-5p enhanced DLL4 expression. Thus, the expression of DLL4 was negatively correlated with the expression of miR-182-5p. Moreover, DLL4 had been proved to be involved in the malignant behaviors of renal cancer in previous studies [37].

Delta-like ligand 4 (DLL4), one of the ligands of Notch receptors, is predominantly expressed in the endothelial cells and has been shown to play a pivotal role in regulating tumor angiogenesis [38-45]. Some studies reveal a role for DLL4 in tumorigenesis in several cancers, including $\mathrm{T}$ acute lymphoblastic leukemia (T-ALL) [46], and glioblastoma [47] etc. We found that overexpressing of DLL4 reverses malignant phenotypes inhibition of renal cancer cells induced by silencing UCA1. DLL4 overexpression significantly reversed cell proliferation inhibition and migration of renal cancer cells induced by silencing UCA1, and significantly reversed cell apoptosis promotion of renal cancer cells induced by silencing UCA1. DLL4-NOTCH signaling is critical for the progression of renal cancer cells.

In brief, further experiments demonstrated that knockdown of UCA1 increased miR-182-5p expression and subsequently inhibited the expression of DLL4 in a ceRNAdependent manner. Moreover, knock-down of miR-1825p reversed DLL4 expression and DLL4 overexpression reversed the malignant phenotype inhibition of renal cancer cells induced by silencingUCA1.This study is giving us a novel point of view for specific molecular targets in human cancers, especially renal cancers, and it deepened our understanding of the relationship between IncRNA,miRNA and proteins in disease progression, and provides us a direction to further discover the diseases' occurrence mechanism in the future, and to overcome and conquer the fatal disease etc. Maybe, it can be converted into the more freshly and validly curative mean for the renal carcinomas. It may be a bright development prospect to radically cure renal cancer that could alter the current dilemma of treatment for the advanced renal cancer.

\section{Conclusions}

Our study reveals that UCA1 functions as a miRNA sponge to positively regulate DLL4 expression through sponging miR-182-5p and subsequently promotes the malignant phenotypes of renal cancer cells, thus playing an oncogenic role in renal cancer pathogenesis. The results of this study provide a new basis for studying the mechanism of the occurrence and development of renal cancer. Cumulatively, our results suggest that UCA1miR-182-5p-DLL4 axis is involved in proliferation migration, apoptosis and progression of renal cancer. UCA1 is a powerful tumor biomarker, which highlight its potential clinical utility as a promising diagnostic and therapeutic target of renal cancer.

\section{Abbreviations}

ANOVA: Analysis of Variance; CCK-8: Cell Counting Kit-8; CeRNA: Competing endogenous RNA; DLL4: Delta-like ligand 4; EdU: Ethynyl-2-deoxyuridine; IDVs: Integrated density values; IncRNAs: Long non-coding RNAs; LVRNA: Lentivirus shRNA; miRNAs: MicroRNAs; PVDF: Polyvinylidene Fluoride; qPCR: Quantitative polymerase chain reaction; RCC: Renal cell carcinoma; SDS-PAGE: SDS-polyacrylamide gel electrophoresis; shNC: Short hairpin negative control; shRNAs: Short hairpin RNAs; T-ALL: T acute lymphoblastic leukemia; TNM: Tumor Node Metastasis; UCA1: Urothelial cancer associated 1

\section{Supplementary information}

The online version contains supplementary material available at https://doi. org/10.1186/s12943-020-1132-x.

Additional file 1: Table S1. The primers for real-time QPCR. Table S2.

Antibodies used for Western blots.

\section{Acknowledgements}

Neither the entire paper nor any part of its content has been published or has been accepted elsewhere. It is not being submitted to any other journal.

\section{Authors' contributions}

The authors are indebted to the donors, whose names were not included in the author list, but who participated in this program. All authors read and approved the final manuscript.

\section{Funding}

The present study was supported by grants from the National Natural Science Foundations of China (grant no. 31700720), project of Chengguan District Science and Technology Bureau of Lanzhou city (grant no. 2017SHFZ0029), the Fundamental Research Funds for the Central Universities (Izujbky-2018-59), the Lanzhou University Innovation and Entrepreneurship Cultivation Program (cxcy201902), and Cuiying Graduate Supervisor Applicant Training Program Of Lanzhou University Second Hospital (201806). Cuiying Scientific and Technological Innovation Program of Lanzhou University Second Hospital (grant no. CY2019-MS17).

\section{Availability of data and materials}

All authors are responsible for the truth and reliability of the article data.

Ethics approval and consent to participate

The study was approved by the institutional research ethics committee of The Second Hospital of Lanzhou University.

\section{Consent for publication}

If this article is accepted, we will agree to publish it and transfer the copyright to academic journals and your publishing company.

\section{Competing interests}

The authors declare that they have no competing interests.

\section{Author details}

${ }^{1}$ Department of Urology, Institute of Urology, Gansu Nephro-Urological Clinical Center, Key Laboratory of Urological Diseases in Gansu Province, Lanzhou University Second Hospital, Lanzhou 730030, Gansu, China. ${ }^{2}$ School of Radiation Medicine and Protection, Medical College of Soochow University, Collaborative Innovation Center of Radiological Medicine of Jiangsu Higher Education Institutions, Suzhou 215123, China. ${ }^{3}$ Department of Nephrology, Second Hospital Lanzhou University Second Hospital, Lanzhou 730000, Gansu, China. ${ }^{4}$ Medical School, Northwest Min Zu University, Lanzhou 730030, Gansu, China.

Received: 24 July 2019 Accepted: 5 January 2020

Published online: 29 January 2020

\section{References}

1. Zhou H, Tang K, Liu H, et al. Regulatory network of two tumor-suppressive noncoding RNAs interferes with the growth and metastasis of renal cell carcinoma. Mol Ther Nucleic Acids. 2019;16:554-65. 
2. Li J, Zhuang C, Liu Y, et al. Synthetic tetracycline-controllable shRNA targeting long non-coding RNA HOXD-AS1 inhibits the progression of bladder cancer. J Exp Clin Cancer Res. 2016;35(1):99.

3. Chen M, Zhuang C, Liu Y, et al. Tetracycline-inducible shRNA targeting antisense long non-coding RNA HIF1A-AS2 represses the malignant phenotypes of bladder cancer. Cancer Lett. 2016;376(1):155-64.

4. Li J, Zhuang C, Liu Y, et al. shRNA targeting long non-coding RNA CCAT2 controlled by tetracycline-inducible system inhibits progression of bladder cancer cells. Oncotarget. 2016;7(20):28989-97.

5. Zhuang C, Li J, Liu Y, et al. Tetracycline-inducible shRNA targeting long noncoding RNA PVT1 inhibits cell growth and induces apoptosis in bladder cancer cells. Oncotarget. 2015;6(38):41194-203.

6. Chen M, Li J, Zhuang C. Increased IncRNA ABHD11-AS1 represses the malignant phenotypes of bladder cancer. Oncotarget. 2017;8(17):28176-86

7. Zhuang $C$, Huang $X$, Zhuang $C$, et al. Synthetic regulatory RNAs selectively suppress the progression of bladder cancer. J Exp Clin Cancer Res. 2017; 36(1):151.

8. Gu P, Chen X, Xie R, et al. A novel AR translational regulator IncRNA LBCS inhibits castration resistance of prostate cancer. Mol Cancer. 2019;18(1):109.

9. Zhang L, Meng X, Zhu XW, et al. Long non-coding RNAs in Oral squamous cell carcinoma: biologic function, mechanisms and clinical implications. Mol Cancer. 2019;18(1):102

10. Xu S, Wang P, Zhang J, et al. Ai-IncRNA EGOT enhancing autophagy sensitizes paclitaxel cytotoxicity via upregulation of ITPR1 expression by RNA-RNA and RNA-protein interactions in human cancer. Mol Cancer. 2019; 18(1):89

11. Wang X, Yang J, Guo G, et al. Novel IncRNA-IUR suppresses Bcr-Abl-induced tumorigenesis through regulation of STAT5-CD71 pathway. Mol Cancer. 2019;18(1):84.

12. Trimarchi T, Bilal E, Ntziachristos P, et al. Genome-wide mapping and characterization of Notch-regulated long noncoding RNAs in acute leukemia. Cell. 2014;158(3):593-606.

13. Kotzin JJ, Spencer SP, McCright SJ, et al. The long non-coding RNA Morrbid regulates Bim and short-lived myeloid cell lifespan. Nature. 2016;537(7619): 239-43.

14. Giorgetti L, Lajoie BR, Carter AC, et al. Structural organization of the inactive X chromosome in the mouse. Nature. 2016;535(7613):575-9.

15. Sallam T, Jones MC, Gilliland T, et al. Feedback modulation of cholesterol metabolism by the lipid-responsive non-coding RNA LeXis. Nature. 2016; 534(7605):124-8.

16. Wang $\mathrm{CJ}$, Zhu CC, XU J, et al. The IncRNA UCA1 promotes proliferation, migration, immune escape and inhibits apoptosis in gastric cancer by sponging anti-tumor miRNAs. Mol Cancer. 2019;18(1):115.

17. Wang XS, Zhang Z, Wang HC, et al. Rapid identification of UCA1 as a very sensitive and specific unique marker for human renal carcinoma. Clin Cancer Res. 2006;12(16):4851-8.

18. Wang F, Li X, Xie X, et al. UCA1, a non-protein-coding RNA up-regulated in renal carcinoma and embryo, influencing cell growth and promoting invasion. FEBS Lett. 2008:582(13):1919-27.

19. Li JY, Ma X. Overexpression of long non-coding RNA UCA1 predicts a poo prognosis in patients with esophageal squamous cell carcinoma. Int J Clin Exp Pathol. 2014;7(11):7938-44.

20. Li Z, Niu H, Qin Q, et al. IncRNA UCA1 mediates resistance to cisplatin by regulating the miR-143/FOSL2-signaling pathway in ovarian cancer. Mol Ther Nucleic Acids. 2019:17:92-101.

21. Kong $L$, Wu Q, Zhao L, et al. Upregulated IncRNA-UCA1 contributes to metastasis of bile duct carcinoma through regulation of miR-122/ and activation of the ERK/MAPK signaling pathway. Cell Cycle. 2019;18(11):1212-28.

22. Han C, Tang F, Chen J, et al. Knockdown of IncRNA-UCA1 inhibits the proliferation and migration of melanoma cells through modulating the miR28-5p/HOXB3 axis. Exp Ther Med. 2019;17(5):4294-302.

23. Pei S, Chen J, Lu J, et al. The long noncoding RNA UCA1 negatively regulates Melanogenesis in melanocytes. J Invest Dermatol. 2019. https:// doi.org/10.1016/j.jid.2019.04.029.

24. Horita K, Kurosaki H, Nakatake M, et al. Long noncoding RNA UCA1 enhances sensitivity to oncolytic vaccinia virus by sponging miR-18a/miR182 and modulating the Cdc42/filopodia axis in colorectal cancer. Biochem Biophys Res Commun. 2019. https://doi.org/10.1016/j.bbrc.2019.06.125.

25. Li O, Yi W, Yang P, et al. Long non-coding RNA UCA1 promotes proliferation and invasion of intrahepatic cholangiocarcinoma cells through targeting microRNA-122. Exp Ther Med. 2019;18(1):25-32.
26. Chen Y, Fu Y, Song YF. Increased expression of IncRNA UCA1 and HULC is required for pro-inflammatory response during LPS induced sepsis in endothelial cells. Front Physiol. 2019;10:608. https://doi.org/10.3389/fphys.2 019.00608.

27. Xuan W, Yu H, Zhang X. Crosstalk between the IncRNA UCA1 and microRNAs in cancer. FEBS Lett. 2019. https://doi.org/10.1002/1873-3468.134 70.

28. He C, Lu X, Yang F, et al. LncRNA UCA1 acts as a sponge of miR-204 to upregulate CXCR4 expression and promote prostate cancer progression. Biosci Rep. 2019;39(5):1-11. https://doi.org/10.1042/BSR20181465.

29. Li D, Hao S. Long non-coding RNA UCA1 exerts growth modulation by miR15a in human thyroid cancer TPC-1 cells. Artif Cells, Nanomed Biotechnol. 2019:47(1):1815-22.

30. Gong J, Lu X, XU J, et al. Coexpression of UCA1 and ITGA2 in pancreatic cancer cells target the expression of miR-107 through focal adhesion pathway. J Cell Physiol. 2019;234(8):12884-96.

31. Sang Y, Chen B, Song X, et al. circRNA_0025202 regulates tamoxifen sensitivity and tumor progression via regulating the miR-182-5p/FOXO3a Axis in breast cancer. Mol Ther. 2019. https://doi.org/10.1016/j.ymthe.2019. 05.011.

32. Cao MQ, You AB, Zhu XD, et al. miR-182-5p promotes hepatocellular carcinoma progression by repressing FOXO3a. J Hematol Oncol. 2018;1 1(1):12.

33. Qin SB, Peng DY, Lu JM. MiR-182-5p inhibited oxidative stress and apoptosis triggered by oxidized low-density lipoprotein via targeting toll-like receptor 4. J Cell Physiol. 2018;233(10):6630-7.

34. Li Y, Chen S, Shan Z, et al. miR-182-5p improves the viability, mitosis, migration, and invasion ability of human gastric cancer cells by downregulating RAB27A. Biosci Rep. 2017;37(3). https://doi.org/10.1042/BSR201 70136.

35. Liang Q, Chen H, Xu X. miR-182-5p attenuates high-fat-diet-induced nonalcoholic steatohepatitis in mice. Ann Hepatol. 2019;18(1):116-25 10.560

36. Jia XN, Yin SD, Wei Y. MiR-182-5p inhibited proliferation and migration of ovarian cancer cells by targeting BNIP3. Eur Rev Med Pharmacol Sci. 2019; 23(8):3270-6.

37. Miles KM,Seshadri M,Ciamporcero E, et al. Dll4 blockade potentiates the anti-tumor effects of VEGF inhibition in renal cell carcinoma patient-derived xenografts .PloS One. 2014;9(11):e112371.

38. McClements $\mathrm{L}$, Annett $\mathrm{S}$, Yakkundi $\mathrm{A}$, et al. FKBPL and its peptide derivatives inhibit endocrine therapy resistant cancer stem cells and breast cancer metastasis by downregulating DLL4 and Notch4. BMC Cancer. 2019;19(1):351.

39. Peng J, Zhao S, Li Y, et al. DLL4 and Jagged1 are angiogenic targets of orphan nuclear receptor TR3/Nur77. Microvasc Res. 2019;124:67-75.

40. Zheng X, Narayanan S, Sunkari VG, et al. Triggering of a Dll4-Notch1 loop impairs wound healing in diabetes. Proc Natl Acad Sci U S A. 2019;116(14): 6985-94.

41. Jaud M, Philippe C, Van Den Berghe L, et al. The PERK branch of the unfolded protein response promotes DLL4 expression by activating an alternative translation mechanism. Cancers. 2019;11(2). https://doi.org/10.33 90/cancers11020142

42. Boardman R, Pang V, Malhi N, et al. Activation of Notch signaling by soluble DII4 decreases vascular permeability via a CAMP/PKA-dependent pathway. Am J Physiol Heart Circ Physiol. 2019;316(5):H1065-75.

43. Un W, Li J, Li Y, et al. Gamma-secretase inhibitor, DAPT, prevents the development of retinopathy of prematurity in a rat model by regulating the Delta-like ligand 4/Notch Homolog-1 (DLL4/Notch-1) pathway. Med Sci Monit. 2019;25:492-9.

44. Nakano T, Katsuki S, Chen M, et al. Uremic toxin Indoxyl sulfate promotes Proinflammatory macrophage activation via the interplay of OATP2B1 and DII4-Notch signaling. Circulation. 2019;139(1):78-96 10.1161.

45. Chen L, Gu T, Li B, et al. Delta-like ligand 4/DLL4 regulates the capillarization of liver sinusoidal endothelial cell and liver fibrogenesis. Null. 2019. https:// doi.org/10.1016/.j.bbamcr.2019.06.011.

46. Minuzzo S, Agnusdei V, Pusceddu I, et al. DLL4 regulates NOTCH signaling and growth of T acute lymphoblastic leukemia cells in NOD/SCID mice. Carcinogenesis. 2015;36(1):115-21.

47. Qiu XX, Chen L, Wang CH, et al. High delta-like ligand 4 (DLL4) is correlated with peritumoral brain edema and predicts poor prognosis in primary glioblastoma. Medicine. 2014;93(8):e57.

48. Zhuang C, Ma Q, Zhuang C, et al. LncRNA GClnc1 promotes proliferation and invasion of bladder cancer through activation of MYC. FASEB J. 2019; 33(10):11045-59. https://doi.org/10.1096/fj.201900078. 
49. Gong S, Qu X, Yang S, et al. RFC3 induces epithelial-mesenchymal transition in lung adenocarcinoma cells through the Wnt/ $\beta$-catenin pathway and possesses prognostic value in lung adenocarcinoma. Int J Mol Med. 2019; 44(6):2276C88. https://doi.org/10.3892/ijmm.2019.4386.

50. Fatima F. Vesiculated long non-coding RNAs: offshore packages deciphering trans-regulation between cells, cancer progression and resistance to therapies. Non-coding RNA. 2017;3(1):1-23. https://doi.org/10.3390/ncrna301 0010

\section{Publisher's Note}

Springer Nature remains neutral with regard to jurisdictional claims in published maps and institutional affiliations.

Ready to submit your research? Choose BMC and benefit from:

- fast, convenient online submission

- thorough peer review by experienced researchers in your field

- rapid publication on acceptance

- support for research data, including large and complex data types

- gold Open Access which fosters wider collaboration and increased citations

- maximum visibility for your research: over $100 \mathrm{M}$ website views per year

At $\mathrm{BMC}$, research is always in progress.

Learn more biomedcentral.com/submissions 